\title{
Descartes: entre la psicología racional y la antropología filosófica
}

Fermín Cebrecos

Universidad de Lima

Recibido: 5 de mayo de 2014 / Aprobado: 24 de junio de 2014

La relación cartesiana entre psicología racional y antropología filosófica se plantea aqui a partir del concepto de sustancia. El dualismo ontológico de las dos sustancias finitas (res cogitans y res extensa), tan taxativamente expuesto en las Meditaciones metafísicas, sufre una restricción significativa en el Traité de l'homme y en De passionibus animae, obras en las que hay una referencia explícita a la glándula pineal como punto físico de unión entre mente y cuerpo. El intento por explicar esta interacción desde la fisiología ubica a Descartes entre la psicología racional, que define la naturaleza humana solo como alma, y la antropología filosófica, para la que el ser del hombre no puede formularse sin el recurso a la unidad psicosomática.

sustancia / psicología racional / antropología filosófica / glándula pineal

\section{Descartes: Relationship between rational psychology and philosophical anthropology}

The purpose of this study is to discuss the Cartesian relationship between rational psychology and philosophical anthropology which originates from the concept of substance. The ontological dualism between the two finite substances (res cogitans and res extensa) specifically introduced in the Metaphysical Meditations is significantly restricted in two further works, the Traité de l'homme and De passionibus animae, in which there is an explicit reference to the pineal gland as the physical contact between mind and body. In this sense, Descartes in his search for an explanation of the mind-body interaction from a physiological point of view promotes a middle ground between a rational psychology, which defines human nature solely as a soul, and a philosophical anthropology, which view human beings as a psychosomatic unity.

substance / rational psychology / philosophical anthropology / pineal gland

Correo electrónico: fcebreco@ulima.edu.pe 


\section{INTRODUCCIÓN}

En el racionalismo cartesiano la sustancia, tanto en su significado ontológico como lógico, es puramente inteligible, y no el concepto de algo imaginable que remite, en su punto genético de partida, a la experiencia sensorial. Ahora bien, si las tres sustancias que componen la totalidad de lo existente (Dios, el alma racional $=$ res cogitans y el mundo corpóreo $=$ res extensa) son, de por sí, autónomas y autosuficientes, ¿cómo podrá establecerse, desde la res cogitans, una relación cognoscitiva "clara y distinta" con las otras dos sustancias?

Descartes, empero, da un paso atrás en su interpretación radical de la autonomía de las sustancias finitas y, mellando su independencia, convierte a Dios en soporte ontológico de las mismas y en garante del conocimiento del mundo y del alma. Sin embargo, al no poder desconocer que existe, de hecho, una interacción entre la res cogitans (mente) y la res extensa (cuerpo), se ve en la obligación de abordar el problema de su mutua relación y recurre, con ese fin, a la glándula pineal como elemento físico de unión.

Las páginas que siguen versan sobre lo que supone el reconocimiento de dicha relación como eventual ruptura del dualismo cartesiano y sobre lo que, además, implica la psicología racional cartesiana de cara a una antropología filosófica que postula, como tesis primera, la unidad mente-cuerpo.
En Die Stellung des Menschen im Kosmos (1927), Max Scheler separó la psicología racional y la antropología filosófica, convirtiéndose en pionero de una línea de pensamiento que tuvo dos continuadores importantes: Helmuth Plessner y Arnold Gehlen. Mas la orientación fenomenológica de Scheler le exigía no renunciar a la fundamentación metafísica de lo específicamente humano. Dos años más tarde de la publicación de El puesto del hombre en el cosmos, señalaba Edwin G. Boring, en A History of Experimental Psychology, que la psicología científica tuvo su origen en Alemania, gracias a una combinación entre la filosofía de la mente y la fenomenología experimental. En Descartes no podría hablarse, en rigor, de una separación entre psicología racional y antropología filosófica; habría, más bien, que postular una relación de simbiosis entre ambas.

\section{ANTECEDENTES ARISTOTÉLICO-TOMISTAS DE LA SUSTANCIA CARTESIANA}

No se pretende aquí reconstruir la génesis y desarrollo históricos de la categoría de la sustancia, sino tan solo considerar algunas raíces que, por su cercanía conceptual, son de fácil detección en Descartes, un pensador tan compenetrado, debido a la enseñanza de los jesuitas recibida en La Flèche, de la gnoseología aristotélico-tomista. Mas el esfuerzo de Aristóteles por integrar el dualismo platónico en una única e idéntica realidad (ousía) no ha de ser- 
vir para soslayar los diversos sentidos de los que este término es objeto.

En efecto, hacerse cargo de lo que, en la intrincada historia de la sustancia, se ganó y se perdió en las traducciones del griego al latín en términos tan poco propensos a la univocidad como, por ejemplo, ousia $=$ substantia e hypokeimenon = subiectum, es enfrentarse a un problema, todavía irresuelto, en el que han cabido diversas tentativas de solución (monismo, dualismo, pluralismo). Para Aristóteles (1990) (cfr. libros VII y VIII de la Metafísica, en especial VII, 1-17, pp. 320-435), la sustancia es la primera categoría del ser y, en cuanto esencia de la cosa o sustancia primera, lleva en sí el soporte de lo que, por su naturaleza, no puede ser sino "accidente". Así, pues, la sustancia primera (ousía proté) se basta ontológicamente a sí misma y, al no necesitar de ningún otro ser como "sujeto de inhesión", se constituye en fundamento o sustrato del ser de los accidentes. Mas esta connotación ontológica quedaría parcialmente entendida sin el recurso a "algo anterior y más conocido", tal como puede verse en $\mathrm{Me}$ tafísica VII, 3 y en Analíticos segundos, A, 2 (Aristóteles, 1990, pp. 326-329; 1988, pp. 316-319): la sustancia segunda (deutéra ousía). Merced a ella, se recupera la primacía del universal sobre el particular (Aristóteles, 1988, pp. 146147), ya que la sustancia primera solo podrá ser interpretada a la luz de lo que constituye su "esencia", explicación que acerca a Aristóteles al eidos platónico. El eidos tiene su correlato latino en el término forma (idea), de ahí que pueda verse en ello la primacía de la causa formal sobre la materia (substantia) en la que dicha causa actúa.

A la connotación ontológica de la sustancia ha de añadírsele, entonces, la dimensión lógico-predicativa, tal como demanda la doctrina aristotélica del capítulo 5 de las Categorías (Aristóteles, 1988, pp. 34-42). En Metafísica VII, 3, 1028 afirma Aristóteles (1990): "De la sustancia (ousía) ${ }^{1}$ se habla, al menos, en cuatro sentidos principales. Los tres primeros, como 'sustancia de cada cosa', son: 'lo que es, el universal y el género'; y 'el cuarto de ellos es el sujeto' (hypokeimenon), el cual es definido como 'aquello de lo que se dicen las demás cosas, sin que él, por su parte, se diga de otra"" (pp. 326-327). Como puede verse, la "sustancia" y el "sujeto" no constituyen seres ontológicamente distintos entre sí; más bien, el sujeto, en cuanto hypokeimenon, es la ousía misma, y esta, debido a que es la primera categoría que puede decirse de algo existente, se identifica con el hvpokei-

1 Xavier Zubiri se manifestó en contra de traducir ousía por esencia, ya que este término equivale, más bien, a quidditas, pero no a substantia. Ousía, según él, adquiere su auténtico significado como "lo substante", es decir, como hypokeimenon (1962, p. 3). La posición discrepante de Valentín García Yebra puede verse en el prólogo a su traducción de la Metafísica (1990, pp. XXIII-XXXIX). 
menon o subiectum. En consecuencia, no hay materia separada de forma, ni tampoco, en equivalencia válida, puede haber sujeto y sustancia como entidades independientes (a, no ser claro está, en la substantia separata del "primer motor inmóvil").

Haciéndose eco de la influencia aristotélica, en el sumario latino Categoriae decem (siglo IV a. C.) -atribuido falsamente a san Agustín, pero probablemente una traducción latina de una obra del griego Temistios-, se afirmaba que todo lo que es puede reducirse a sustancia y que las categorías "no pueden ser conocidas sino por el sujeto" (non possint nisi ex subiectos agnosci). Se hacía hincapié, asimismo, en la permanencia de la sustancia como hypokeímenon o entidad subyacente, y la diferencia que, a este respecto, mantenía con los "accidentes". Un siglo después, Martianus Capella, en De nuptiis Philologiae et Mercurii, identificará al sujeto con la "sustancia primera" (subiectum est prima substantia) y, en idéntica línea de pensamiento, Boecio propondrá, en el capítulo tercero De duabus naturis et una persona Christi, la definición clásica de "persona": naturae rationalis individua substantia ("sustancia individual de naturaleza racional") (Migne, 1996 [2013], vol. LXIV, p. 2). En ella se recoge, por un lado, el legado aristotélico y patrístico, y se prepara, por otro, la interpretación tomista de la sustancia, pero también se plantea el problema acerca de cómo dos sustancias hete- rogéneas pueden constituir, al mismo tiempo, un mismo ser personal.

Citando expresamente el libro V de la Metafísica, Tomás de Aquino confirmará que la sustancia se dice en un doble sentido (dupliciter): como "quididad de la cosa" (quidditas rei) y como "sujeto o sustrato (subiectum vel suppositum) que subsiste en el género de la sustancia". El "sujeto" ha de ser interpretado aquí como base sustentante de los accidentes o categorías ( $S T$, la q. 29, art. 2; cfr. también la quaestio XIX en las Quaestiones disputatae de anima). Esta dimensión lógica de la sustancia como predicamento universal no ha de ocultar, en el plano ontológico, que la individua substantia es para él una "sustancia completa, subsistente por sí y existiendo aparte de otras" (separata ab alia) (ST, III, q. 16, art. 2). Consiguientemente, su esencia es por sí (quod est per se esse) y no se caracteriza, como los accidentes, por tenerla en otro (in alio esse) como "sujeto de inhesión" (Contra Gentiles, I, 25 y ST, I, q. 3, art. 5). (Cfr. Pérez de Laborda, 1996, pp. 278-279).

Parece del todo seguro afirmar que Francisco Suárez, con quien el saber medieval alcanza una de sus síntesis mejor organizadas, no participó del propósito wolffiano de dividir la metafísica en general y en especial; por lo tanto, tampoco habría desligado ni a Dios, ni al alma, ni a la naturaleza del ámbito ontológico que les correspondía. Sin embargo, llama la atención que 
su comentario aristotélico De anima no fuese incluido en las Disputationes metaphysicae (1597), en cuya primera línea la metafísica es conceptuada como scientia quae ens, in quantum ens seu in quantum a materia abstrahit secundum esse, contemplatur. Suárez -o, por lo menos, el renacimiento escolástico, siempre ortodoxo, que él representaba- ha de ser considerado como el pensador más influyente en la filosofía que los jesuitas enseñaban en el colegio de La Flèche, de ahí que Descartes, también en lo que respecta a la sustancia, se identificase con él. La primera parte de las Disputationes metaphysicae constituye una reflexión sobre el concepto, propiedades y causas del ser, mientras en la segunda se pasa de la división del ser en infinito y finito a la distinción entre sustancia y accidentes; finalmente, se aborda el esclarecimiento de la sustancia en cuanto tal (Disputationes metaphysicae 28, 32 y 33-36). Tal vez su aporte innovador más importante esté en cómo explica la relación entre Dios y el ser humano, relación que no aparece entre este último y el ser en general. Su recurso a la "potencia obediencial activa" implica una cooperación simultánea entre Dios y la criatura que tendrá que salvaguardar la libertad humana y que, en consecuencia, dista mucho de ser una respuesta ocasionalista, como sucederá más tarde con los vacíos que, a este respecto, dejó Descartes.
La filiación aristotélico-tomista de la que se nutre la metafísica cartesiana no podrá eludir, en lo tocante a la sustancia, tres características fundamentales:

a) La sustancia es lo que permanece "debajo" de las modificaciones accidentales (sustancia primera $\mathrm{o}$ substantia individualis). El infinitivo latino sub-stare, del que se deriva substantia (traducción del griego ousía), implica un "estar debajo de", pero concediendo soporte y fundamento a lo que se encuentra encima.

b) La sustancia es el sujeto o ser del que se predican todas las propiedades de la sustancia primera. Esta sustancia segunda se identifica con el subiectum (traducción del griego hypokeimenon), un participio de pretérito pasivo del verbo subicere, que significa "arrojar, lanzar hacia afuera", pero que se vincula genéticamente al verbo iacere. Ahora bien, si le antepone la preposición sub (subiacere), resulta fácil encontrarle parentesco significativo con sub-stare $\mathrm{y}$, por lo mismo, puede decirse que sujeto y sustancia poseen una raíz latina que los identifica en su cualidad de servir de soporte a lo que, de por sí, necesita un sujeto de inhesión: los accidentes.

c) Al no tener su ser en otro sino en sí, la sustancia posee un ser independiente o, lo que es lo mismo, no es relativa a ninguna otra entidad. No 
se identifica con sus atributos o propiedades, pues estos se fundamentan en la sustancia y, por tanto, no son absolutos. Al precisar de la sustancia como sujeto de inhesión, también los accidentes son seres cuya esencia consiste en un estar en otro (esse in = innesse $=$ inherido a otro), con lo cual pueden ser calificados de realidad parasitaria de la sustancia.

La filosofía cartesiana se nutre de este subsuelo. Pero Descartes, pese a su filiación aristotélico-tomista, encontrará también en el pensamiento de $\mathrm{M}$. de Montaigne, P. Charron y F. Sánchez un escepticismo antropocéntrico que le conducirá, mediante la duda metódica, a ubicar el saber sobre el hombre (La vraye science et le vray étude de l'homme, c'est l'homme, había dicho Charron) en una psicología racional en la que el "alma" se identifica con la sustancia humana, y no, como en la antropología aristotélica, con la unidad de un "animal racional". No ha de olvidarse, finalmente, que Descartes quedaría parcialmente interpretado sin las repercusiones de la nuova scienza, y no solo en lo tocante a la matematización de la naturaleza, sino también a la importancia concedida por él a la experimentación.

\section{LA SUSTANCIA CARTESIANA}

Trasladarse desde estos antecedentes filosóficos al sustancialismo cartesiano no resulta una empresa teórica difícil.
En síntesis, de la doctrina aristotélicotomista puede afirmarse, como ya se ha visto, que la sustancia es una cosa (res) que posee su ser en y por sí misma, y que no necesita de ninguna otra cosa para ser lo que es. Lo mismo sostendrá Descartes (1987b): "No podemos entender por sustancia sino una cosa que existe de tal modo que no requiere de ninguna otra cosa para existir" (Per substantiam nihil aliud intelligere possumus quam rem quae ita exsistit, ut nulla alia re indigeat ad existendum) (p. 52). Dicha sustancia, empero, es una "propiedad, cualidad o atributo cuya idea real está en nosotros"; se trata, por consiguiente, de una idea innata (1987a, p. 70). Dicho de otro modo: lo que es en sí se concibe también por sí (per se concipitur), infiriéndose que el concepto de sustancia — como asegurará más tarde Spinoza- tampoco necesita del concepto de ninguna otra cosa para ser definido (Ética I, def. iii). En Descartes, la noción de sustancia entraña también el "concebirse por sí misma", es decir, la incapacidad ontológica de poder reducirse a otra cosa, pero él no identificaba, como Spinoza, la sustancia de Dios con la de la naturaleza (Deus sive natura).

La sustancia cartesiana no puede predicarse unívocamente. Hay una sustancia infinita (es decir, Dios = sive Deus) y dos sustancias creadas finitas: la substantia finita extensa, sive corpus y la substantia finita cogitans, sive mens (Descartes, 1987b, pp. 52- 
53; 1977a, pp. 70-72). No se trata, en consecuencia, de un monismo sustancial, aunque salta a la vista que sin el concurso divino no podrían existir las sustancias finitas. Las citas cartesianas que pueden traerse a colación en este contexto son tan numerosas como susceptibles de repetición.

Aunque el grado de dependencia divina que caracteriza a ambas sustancias sea similar, no significa que entre ellas no se establezca una jerarquía o que se suprima el dualismo. El atributo principal de la sustancia espiritual es pensar $y$, por ende, nada de lo que está "fuera de mí” (materia inanimada, seres vivos, accidentes vinculados a lo corpóreo) puede definir "qué soy yo". Y lo mismo sucede cuando uno se aboca a reflexionar sobre la naturaleza de los cuerpos. Sin saber a ciencia cierta todavía si lo corpóreo existe, será la sustancia pensante, y solo ella (sola mente percipere), la que decidirá que, de existir, necesariamente tendrá que ser "flexible" y "extenso". Pero estas dos características de lo físico no se originan, como en el realismo, en experiencias sensoriales; son exigencias que, actuando de universal cognoscente, impone la res cogitans a la sustancia finita corpórea. Por consiguiente, a la pregunta sobre lo que sean la flexibilidad y la extensión (Quid vero est hoc flexibile, mutabile? Quid extensum?) (Descartes, 1977a, p. 54) solo puede responderse desde la otra sustancia finita: la res cogitans.
La autoconciencia de ser pensante es, por consiguiente, la definición más clara y distinta de la naturaleza humana. Y a ella no se llega por la deducción que, a primera vista, puede derivarse del "ergo" presente en la formulación del Discurso del método: Cogito, ergo sum (Descartes, 1987a, p. 69). Se trata, más bien, de una intuición de esencia que Descartes había enunciado así en la versión francesa de dicha obra: Je pensé, donc je suis, y que en latín podría traducirse legítimamente como cogitans sum ("pensando, existo"), fórmula que aparecía, por cierto, en el primer esbozo de la Primera meditación (1629). En esta aprehensión intuitiva, la verdad es una cuestión que solo la mente dirime; por lo tanto, no podrá definirse, a la manera del realismo gnoseológico, como "adecuación entre el objeto y la mente" (adaequatio rei et intellectus). La intuición, tal como se lee en la regla III de las Regulae ad directionem ingenii, es un "concepto indubitable de la mente pura y atenta, el cual se origina en la sola luz de la razón" (mentis purae et attentae non dubium conceptum, qui a sola rationis luce nascitur). Así, pues, el alma es definida exclusivamente como conciencia, y es en la cogitatio donde se descubre la igualdad res cogitans $=$ substantia $=$ animus $=$ ego $(\mathrm{ser}$ pensante-sustancia-alma-yo) (Descartes, 1987a, pp. 69-71).

Pese a la incomunicación establecida entre las sustancias, si se afirma - como hace Descartes (1977a) - que 
la sustancia de lo corpóreo, al igual que la duración y el número, proceden de la representación de mí mismo (p. 80), se plantea no solo una jerarquía entre las sustancias, sino una relación gnoseológica en la que la res cogitans, como verdad fundamental y fundamentante, posibilita la existencia de la res exten$s a$. La certeza de que "los cuerpos no son conocidos propiamente ni por los sentidos ni por la facultad de imaginar, sino solo por la facultad de conocer" (sed a solo intellectu percipi) (Descartes, 1977a, p. 58) muestra la jerarquía de la sustancia pensante en el ordo cognoscendi. De igual modo, cuando Descartes (1977a) aborda la explicación de las dos características de la res cogitans más vinculadas a la experiencia sensorial (res imaginans y res sentiens), afirmará que imaginar no es otra cosa que contemplar (con los ojos de la razón) la imagen que los sentidos han impreso, y que el sentir solo puede ser verdadero cuando es identificado con "yo pienso que siento" (pp. 50 y 58). Sin embargo, ni la verdad ni la sustancia del cogito han de erigirse, en el orden del conocer y en el orden del ser, en la verdad y la sustancia primordiales.

Ya en la síntesis de la segunda meditación, que Descartes ofrece en la Synopsis sex sequentium meditationum, se ve claramente que mente y cuerpo son sustancialmente distintos (substantias realiter a se mutuo distinctas), pero, en cuanto cosas creadas, deben el ser de su creación a Dios (a Deo creari deben ut existant) y solo pueden ser "corruptibles" (es decir, tener un fin en el tiempo) si la voluntad divina así lo decide. El cuerpo humano, sin embargo, al estar compuesto de atributos principales que ontológicamente han de ser considerados como accidentes, morirá; "la mente, sin embargo, es inmortal por naturaleza" (en la versión francesa la mente se denomina l'ame de l'homme) (Descartes, 1977a, p. 24). La sustancia divina es infinita, independiente, inteligente en grado sumo, sumamente poderosa, y en ella han sido creados tanto el yo como todo lo que hay (si quid aliud existat). Incluso la posibilidad de pensar una sustancia infinita se debe a que, a pesar de la finitud de la sustancia pensante, Dios le otorga esa facultad (Descartes, 1977a, pp. 80-82).

Si las dos sustancias finitas necesitan de lo otro de sí y reciben de Dios la causa última de su existencia (su esencia, por tanto, no supone necesariamente la existencia, como sí sucede con la esencia divina), entonces, se elimina la causalidad propia y se abren las puertas a un ocasionalismo teológico en el que Dios se impone como causa eficiente última. Por consiguiente, incluso la certeza de las demostraciones geométricas, que había quedado en duda con la admisión de la hipótesis del genio maligno, dependerá ahora del conocimiento divino (a cognitione Dei pendere) (Descartes, 1977a, p. 28). Queda 
al descubierto, entonces, la precariedad ontológica de ambas sustancias.

Esta indigencia entitativa también se manifiesta en la parte gnoseológica. $\mathrm{Si}$ bien Descartes (1977a) — y en eso radicaría también su "modernidad" frente a la filosofía escolástica- podía atribuir a la autoría del solo poder de la razón, y no a Dios, tanto el método de la duda como el hallazgo de la primera verdad (pp. 42-44), tendrá que volver sobre sus pasos y, con el fin de recuperar la verdad de las proposiciones de las ciencias formales y empíricas, desechar la hipótesis de un "engañador poderosísimo" (deceptor potentissimus) y reemplazarla por la segura convicción de que Dios existe y de que, por ser creador de todo e infinitamente bueno, garantiza la ciencia y la sabiduría (epistéme y sophía). De este modo, reaparecen también los objetos de la metafísica especial en la perspectiva de un triadismo jerarquizado: Dios (la sustancia infinita), el alma y el mundo (las sustancias finitas). Dios se erige, por consiguiente, en el factor soberano que hace posible que las tres sustancias se comuniquen entre sí, tanto ontológica como gnoseológicamente.

\section{LA PSICOLOGÍA RACIONAL}

Desde que Philipp Melanchthon, en el siglo XVI, introdujo en el vocabulario filosófico el término psicología (psyché legein significa, en sus raíces etimológicas, "decir algo racional sobre el alma"), quedó en claro la inclinación a identificar la psyché con la esencia racional del hombre. Descartes contribuyó a reforzar dicha tendencia con la ecuación mens sive animus ("mente, es decir, alma") para definir la esencia humana. Por esta causa, cuando en 1734 Christian Wolff publicó su Psychologia rationalis, obra en la que se separaba a la psicología racional de la psicología empírica, se concedió a la primera la carta de ciudadanía de un saber deductivo y se la incorporó a la metaphysica specialis como una rama que registraba antecedentes históricofilosóficos muy lejanos y que estaba constituida por la reflexión acerca de lo que, en último término, es el ser humano. Gracias a Wolff - aunque no fuera esa su intención-, la psicología racional y la psicología empírica siguieron caminos separados hasta que la psicología científica - sin desmerecer aquí los aportes de Weber, Fechner, Müller y C. Bernard-hizo su aparición en 1873-1874 con los Grundzüge der physiologischen Psychologie, de Wilhelm M. Wundt. Merced a la interpretación fisiológica de la psicología, se pretendió despedirse de su anclaje metafísico y, al mismo tiempo, advertir que sin la comprensión del hombre como unidad psicosomática no podría lograrse una auténtica antropología filosófica.

Esta concepción unitaria aparece ya con claridad en sus Beiträge zur Theorie der Sinneswahrnehmung (1862). Wundt sostiene, estableciendo el carácter inductivo de la psicología, que no ha de 
recurrirse a priori al alma como fuente de conocimiento. Refiriéndose al apotegma leibniziano: "Nada hay en el intelecto (intellectus) que antes no haya estado en la experiencia sensorial", escribe:

Estoy muy lejos de depositar de nuevo en este intellectus todo un mundo de representaciones innatas en el alma, como hizo Leibniz, entendiendo por intellectus aquel dato de la experiencia del desarrollo lógico, en el cual no está el conocimiento mismo, sino la posibilidad de su adquisición (Beiträge, 1862, p. XXIII. Cf. Caparrós, 1980, p. 15).

Descartes no definió al ser humano ni como ser inanimado ni como ser animado. Empleó el término latino anima para, fiel a su etapa de realista gnoseológico, referirse al soplo vital (pysché, spiritus), mas esta "alma" (que se nutre, se mueve y siente) no se identifica con el animus (alma racional = res cogitans), de ahí que el ser humano no pueda definirse, en su sustancia o esencia, como un soplo o un fuego tenue y sutil (non ventus, non ignis, non vapor, non halitus) (Descartes, 1977a, pp. 44 y 50). Si el yo existe si y solo si piensa que existe, podrá postularse que, al no estar determinado por un cuerpo que, de por sí, al no tener conciencia de su existencia, no existe, su duración en el tiempo será tan larga como lo es su capacidad de pensar. Por consiguiente, mientras el espíritu (anima) de los seres vivos está limitado ontológicamente por una vida efímera, el alma racional (animus) perdura en el tiempo y no se halla condicionada en su destino final por un "soplo sutil" que, inevitablemente, tendrá que "exhalarse" y dejar a lo animado convertido en cadáver. Cualquier postulado acerca de la unión entre anima y animus, así como acerca del nexo entre la materia inanimada y la animada, ha de tener en cuenta su carácter transitorio, el cual es otra prueba más de la inferioridad ontológica con respecto a la mente o alma (mens sive animus) (Descartes, 1977a, p. 46). La inherencia material, ínsita tanto en los seres vivos como en la naturaleza meramente corpórea, no ha de ser objeto de la psicología racional; será, más bien, la psicología empírica wolffiana quien deberá hacerse cargo de su ámbito de estudio.

Por su sujeción al dualismo, Descartes (2007a) no podrá definirse a sí mismo como animal rationale (p. 44). $\mathrm{Su}$ escisión de la realidad en res cogitans y res extensa rompió la unidad aristotélica del principio formal (mente) y del principio material (cuerpo), atribuyendo a este un determinismo mecanicista que priva de automovimiento a los animales y los convierte en máquinas, porque son solo res extensa y no poseen cogitatio alguna. Las causas del movimiento de los cuerpos vivos no pueden proceder, por consiguiente, de nada vinculado a lo racional (esto es, a la conciencia); han de ser, más bien, similares a las de la res extensa $(D e$ 
passionibus animae I, 1-17; cf. Adams y Tannery, 1957, p. 58).

En planteamiento tan radicalmente binario no cabe la "unión sustancial" que Aristóteles postulaba, y que en la escolástica medieval fue corroborada interpretando el alma como principio de la vida biológica, sensitiva y animal. Para Descartes, habría tan solo una unidad de composición en la que los sumandos (mente y materia) son magnitudes ontológicamente distintas: "Nada corpóreo escribió en las Cuartas objeciones, en réplica a Arnauld pertenece a la esencia del ser humano, que es, por consiguiente, enteramente espíritu", siguiéndose de ello "la definición del hombre como un espíritu que hace uso de su cuerpo". Señala también que alma y cuerpo son sustancias completas en un sentido, pero incompletas en otro. Y añade: "Alma y cuerpo son sustancias incompletas, referidas al hombre, que es la unidad, que juntos forman" (Descartes, 1977a, pp. 180-187). En dicha unidad sigue ocupando un rango inferior lo relacionado con lo corpóreo, ya que todos los modos de unión de cuerpo-alma se fundamentan en que los sentidos no revelan la naturaleza de las cosas, sino tan solo si son nocivas o útiles. Ello no obstante, la unio compositionis exigirá, a fin de explicar la aporía del movimiento somáti- co voluntario, la apelación a un punto de unión que, paradójicamente, en De passionibus animae I, 31-41, la última obra publicada en vida de Descartes (1649) y que se inicia con la corroboración del dualismo, supondrá una abdicación de su concepto de sustancia y seguirá ubicándose, como en el Traité de l'homme (1633), en la glándula pineal.

\section{LA GLÁNDULA PINEAL: UBICACIÓN Y FUNCIONES}

El pensamiento, por más abstracciones que pueda hacer de lo dado a los sentidos, se encuentra ante un factum insoslayable: entre lo corpóreo y lo espiritual se dan conexiones que no se explican sin el recurso a su interacción recíproca. Tal vez la interrelación habría que adjudicársela a "las muchas cosas que están en la mente misma" y que no están relacionadas con los sentidos (Descartes, 1977a, p. 58), pero constituye también un hecho, aunque "misterioso", que "experimenta uno en sí mismo sin necesidad de filosofar" (Carta a Isabel, 28 de junio de 1643). Para "salvar" dicho fenómeno no parece quedar otra alternativa que vincular la sustancia racional a la sustancia extensa y, mediante el recurso a un ser material, ofrecer una explicación acorde con la gnoseología racionalista.

2 Este "hecho" fue objeto de un escepticismo radical en Blaise Pascal, el cual —en cita de san Agustín: Civitas Dei XXI, 10 - declaró que el ser humano "no puede concebir lo que es cuerpo, y menos todavía lo que es espíritu, y menos aún cómo un cuerpo puede estar unido a un espíritu” (Pensamientos, p. 84). 
Una vez abandonada la teoría realista del conocimiento, el problema de la unión alma-cuerpo se constituyó en una preocupación siempre presente en el pensamiento de Descartes. Sin embargo, ese interés no se resolvió en una tarea totalmente cumplida y, debido a ello, no puede atribuirse a su obra ser la primera explicación sistemática de la relación mente-cuerpo. Durante su prolongada permanencia en Holanda, desde 1628 hasta su viaje a Suecia en 1649, compuso lo que podría denominarse el temario in nuce de la problemática que gira en torno a dicha relación: el Traité de l'homme (1633, aunque publicado póstumamente en 1664) y De passionibus animae (1649). La publicación de su tratado sobre el hombre, concebido inicialmente como el capítulo 18 de Le monde ou le traité de la lumiére, quedó suspendida al enterarse Descartes, en noviembre de 1633 , de la condena a Galileo. Es cierto que la ruptura de la independencia ontológica de las sustancias finitas podría conducir a una misma unidad de destino y, con ello, a una posible negación de la inmortalidad del alma, pero no es este el lugar propicio para despejar la incógnita acerca de si la no publicación de la obra ratifica la convicción dualista de su autor, o si, por el contrario, en consonancia con la hi- pótesis de Maxime Leroy en Descartes, le philosophe au masque (1929), contribuyó a enmascarar, ya para siempre, su auténtico pensamiento ${ }^{3}$.

En su Tratado del hombre describe Descartes el mecanismo de la reacción automática en respuesta a los estímulos externos. Cierto es que en la parte $\mathrm{V}$ del Discurso del método (Descartes, 1987a, p. 97) hace referencia al "automatismo de los brutos", y que en las Meditaciones metafísicas lo califica de percepción errónea (Descartes, 1977a, p. 50), pero en el artículo 2 de la obra de 1633 había planteado una tesis más radical: "Supongo que el cuerpo no es otra cosa que una estatua o máquina de tierra a la que Dios forma con el propósito de hacerla tan semejante a nosotros como sea posible". E iniciando su búsqueda hacia un vínculo entre máquina y alma, añadirá en el artículo 28: "Cuando Dios una un alma racional a esta máquina, otorgará a esta alma como sede principal el cerebro" (Descartes, 1990, pp. 22 y 50 , respectivamente).

Es sabido el interés que en el Renacimiento adquirieron los autómatas (relojes, molinos, figuras religiosas y cortesanas). El automatismo cartesiano, sin embargo, no fue interpretado en 1633 a la manera de las Meditaciones metafísicas de 1641. Descartes asevera

3 Sobre el particular, así como sobre la "consideración idealizada" del "avance rectilíneo" de la obra cartesiana (duda metódica-formulación del mecanicismo-metafísica de la subjetividad), que él reemplaza por el "avance cronológico real”, cf. el magnífico estudio introductorio a Descartes de Salvio Turró (1989, pp. 7-42). 
en su Traité de l'homme que puede establecerse una "correcta comparación" entre el cuerpo humano y las fuentes que adornan los jardines reales, $\mathrm{y}$ entre la "máquina corporal" y los tubos que forman parte de la mecánica de esas fuentes: los músculos y tendones del cuerpo humano se asemejan a los resortes que las mueven, el corazón es similar al manantial que las nutre y "las concavidades del cerebro" son comparables a "los registros del agua". Y concluye (artículo 16):

Cuando esta máquina posea un alma racional, habrá de estar localizada en el cerebro y su función será comparable a la del fontanero, quien debe permanecer ante los registros donde se reúnen los tubos de esas máquinas, si desea provocar, impedir o modificar en cierto modo los movimientos de la fuente (Descartes, 1990, pp. 35-36).

El automatismo es la exigencia que pone la razón en los seres vivos para conocer su naturaleza, pero no podría explicarse sin sostener que el alma racional y el cuerpo, dos sustancias independientes, establecen contacto mediante la glándula pineal, que es la encargada de trasladar de una sustancia a otra el movimiento voluntario. En el Tratado del hombre se pone de manifiesto, por consiguiente, que el mecanicismo radical resulta insostenible, como también queda recusada la afirmación ocasionalista de que no existe verdadera interacción causal entre alma y cuerpo. Clauberg, La Forge, Geulincx y Malebranche se mostraron, en su afán por preservar el dualismo, más cartesianos que Descartes mismo.

Cabe advertir que en las Meditaciones metafísicas no se negaba la interacción entre mente-cuerpo, pero quedaba subordinada a la res cogitans, subordinación no tan fácil de defender cuando se introduce la glándula pineal como punto físico en el que la interacción se lleva a cabo. Una de las tesis fundamentales de la segunda y sexta meditación hará hincapié en la distinción sustancial entre alma y cuerpo, de tal modo que la una puede existir sin el otro. Expresado de otra manera: la parte inmaterial del hombre, a la cual, por obra divina, está armónicamente subordinada la res extensa, se encuentra totalmente libre de las leyes de la mecánica. Ahora bien, Descartes reconoce que "esta naturaleza mía, dirigida por Dios, nada me enseña con más claridad que tengo un cuerpo que se siente mal cuando siento dolor y que necesita alimento y bebida cuando siento hambre y sed". A través de estas sensaciones (istos sensus) se percata de que está estrechamente ligado y casi mezclado (coniunctum et quasi permixtum) con su cuerpo, de suerte que forma una unidad con él. Pero el dolor no se percibe con la mente, puesto que el yo no está alojado en el cuerpo como un piloto en su navío. Su percepción consiste solo en "confusas determinaciones de la 
conciencia" originadas en la mezcla del espíritu con el cuerpo (nihil aliud sunt quam confusio quídam cogitandi modi ab unione et quasi permixtione mentis cum corpore exorti). Persiste, por tanto, en la autoconciencia la constatación de que nada puede ser conocido con más claridad que la sustancia pensante, ya que ni siquiera Dios puede infundir claridad a una permixtio que implica, como mezcla confusa, una interacción no indubitable (cfr. Descartes, 1977a, pp. 144-146). También en El mundo. Tratado de la luz, Descartes había sostenido la diferencia entre sentir la luz y el objeto que la provoca, esto es, entre la idea y el objeto $(1989$, p. 45). Y en las Notas dirigidas contra un cierto programa (Adam y Tannery, 1957, VIII B, p. 359) ratificará que los objetos externos transmiten a través de los sentidos no ideas, sino, más bien, "algo que da a la mente ocasión para formar esas ideas por medio de una facultad innata".

Como puede verse, no se apela en las Meditaciones metafísicas, tal como había sucedido en De homine, a la glándula pineal (epiphysis cerebri) para explicar que el dolor, que es una percepción del alma, tiene su asiento en ella. Dicha glándula se constituye en punto de contacto entre el alma y el cuerpo, convirtiéndose tanto en el órgano receptor de las impresiones sensoriales externas como en la causa de los movimientos musculares. Es "la parte del cerebro más interior de todas" y en ella el alma ejerce inmediatamente sus funciones.
Descartes afirma que se trata de "una cierta glándula muy pequeña que está situada en el centro de la sustancia cerebral, y que se halla suspendida sobre el conducto por donde los espíritus animales tienen comunicación en sus cavidades interiores con las posteriores", de suerte que, en interacción recíproca, sus movimientos alteran el curso de los movimientos del espíritu, y viceversa (De passionibus animae 1, 30). Ya antes, en 1,10 , había definido a los espíritus animales como "porciones sutiles de la sangre que entran en las cavidades del cerebro". Se trata, en realidad, de cuerpos materiales extremadamente pequeños que se mueven "como las partículas de una llama" y son conducidos a nervios y músculos para impulsar los movimientos del cuerpo (Adam y Tannery, 1957, p. 58).

Descartes estaba familiarizado, sin duda, con la pormenorizada descripción anatómica de esta glándula, conocida en su tiempo como "el lugar donde se localiza el alma", que había proporcionado Andrés Vesalio en su De humani corporis fabrica (1543). Tanto para Galeno como para Vesalio, la glándula pineal era un órgano en forma de piña o bellota que sostenía las venas cerebrales, aunque no pueda asegurarse que lo interpretasen como regulador del flujo de la memoria. Todo parece indicar que el adjetivo pineal adquirió carta de ciudadanía con Thomas Gibson, quien, en 1682, comparó dicha glándula con un "pene suspendido" entre los dos corpo- 
ra quadrigemina situados en la parte dorsal del cerebro medio y que tienen forma de testículos.

El conocimiento de esta doctrina contribuyó a que Descartes admitiese que dicho órgano, al cual calificó de "tercer ojo", representaba el punto de conexión entre el entendimiento y el cuerpo. Privilegiada como "centro anatómico" y elevada a correlato físico del alma, pensó que esta formación endocrina, al no estar presente en ambos lados del cuerpo, estaba investida de una estructura única en la anatomía humana. Descartes consideraba que todos los órganos sensoriales y cefálicos eran dobles, a excepción de la glándula pineal, que era la encargada de integrar la información de los órganos duplicados y que se encontraba situada geométricamente en el centro del cerebro y suspendida sobre los canales que contenían los "espíritus animales". Tan detallada información la recabó de sus visitas, durante su estadía en Ámsterdam, a diversos mataderos de animales para examinar sus cerebros (cfr. también 1987a, pp. 89-96). Después de su muerte en Estocolmo, se encontraron muchas notas y dibujos de la glándula pineal, de los ventrículos cerebrales y de determinados nervios.

Debido, sin embargo, a las técnicas de disección de la época, no era posible asignar a dicha glándula una localización tan precisa como la que Descartes le atribuyó, máxime si se tiene en cuen- ta que las razones que le condujeron a considerar la glándula pineal como centro de control del cuerpo y alojamiento del sensorium commune, esto es, como un asiento del alma en el que convergían todas las sensaciones, fueron, con toda seguridad, de carácter anatómico, promovidas por el notable progreso del conocimiento del sistema nervioso experimentado en la época. Apoyándose en Clarke y O. Malley, afirman LópezMuñoz y Álamo (2000) que él localizaba dicha glándula en la porción rostral del sulcus lateralis del cerebro, el cual conecta el tercer ventrículo cerebral con el cuarto (p. 250).

La función fisiológica encomendada por Descartes a la glándula pineal fue hacerse cargo, en el sistema nervioso, de la percepción del entorno. En ella, que era la parte más importante del cerebro, la sangre se convertía en "espíritus animales", los cuales se extendían por los nervios y, a través de la reordenación de los espacios interfibrilares, ponían el alma en contacto con la información procedente de su alrededor. Mas el alma podía (o no podía) percatarse de las emanaciones diferenciales reportadas por los denominados espíritus animales. Pero si las percepciones ocurrían, entonces, se producía una sensación consciente $\mathrm{y}$, por ende, podía afirmarse que el cuerpo afectaba a la mente. A su vez, en las acciones voluntarias (por ejemplo: yo quiero mover mi brazo, y mi deseo va acompañado del movimiento 
físico ad hoc), el alma emprendía por sí misma la emanación diferencial y testimoniaba así que también puede afectar al cuerpo. Los movimientos externos afectaban a las "fibrillas nerviosas" y estas, a su vez, desplazaban las terminaciones centrales del sistema nervioso, y, mediante el flujo de los espíritus animales galénicos ("sutiles fluidos que ocupan el interior de los ventrículos cerebrales y de los nervios") (López-Muñoz y Álamo, 2000, p. 247), se dirigían hacia una reacción automática (teoría del reflejo). Para Galeno de Pérgamo, los nervios eran tubos huecos por los que discurrían los espíritus animales, causantes de la actividad orgánica. Esta teoría fue retomada a principios del siglo XVIII, pero interpretando dichos espíritus como vibraciones etéreas que ponían en movimiento a los músculos a partir de los nervios conectados con el cerebro, sin recurrir aún a la naturaleza eléctrica del impulso nervioso.

Interesa destacar aquí que la glándula pineal, cartesianamente considerada, se constituye en el puesto de mando desde el que el alma insufla vitalmente su poder a todas las partes del cuerpo, pero también, al mismo tiempo, es dicha glándula la que, desde afuera, recoge lo producido por los estímulos externos y se comunica con el alma (De passionibus animae I, 31-41; cfr. Adam y Tannery, 1957, p. 58). Así, pues, toda sensación no es otra cosa que un modo de conciencia en el que el alma - como afirma Geneviève Rodis-Lewis (1982) - queda afectada por alguna modificación cerebral, efecto, a su vez, de una excitación, externa o interna, recibida mecánicamente por el organismo (p. 27).

La sustancia, en cuanto "naturaleza" o "esencia", tiene en Descartes una clara distribución jerárquica en la disputa por cuál ha de ser el principal "sujeto de inhesión". Si las dos sustancias finitas proceden de Dios y en Él encuentran la justificación racional de su existencia, entonces, no caben dudas acerca de una ontología cartesiana marcada por el teocentrismo. Pero en ella Dios no está "fuera de mí" (mi "intimidad", a la manera de san Agustín, no puede definirse sin Él); todo "lo que está fuera de mí" es, más bien, lo corpóreo (sea animado o inanimado). Por lo tanto, lo corpóreo no podrá ser "sujeto de inhesión" de un yo que, por su autoconciencia, se muestra transparente a una mirada interior que, identificada con la res cogitans, le hace dudar de las experiencias sensoriales, pero no de sí mismo (Descartes, 1987a, pp. 68-71). En este planteamiento, ni el cerebro ni la glándula pineal quedan liberados de una ubicación inferior en la ontología cartesiana.

¿Cuál fue la verdadera intención de Descartes en lo que respecta a la interacción mente-cuerpo? La respuesta no es tan fácil como para ubicarla totalmente en su no publicación del Tratado sobre el alma por temor a la Inquisición. Ya en una carta a Mersenne (25 de noviembre de 1630) se hacía referencia a un "esbozo de metafísica" que 
contendría no solo argumentos en pro de la existencia de Dios, sino también, en un afán apologético de la fe cristiana que lo acompañó durante toda su vida, las pruebas de la existencia "de nuestras almas cuando están separadas del cuerpo". Está claro que si es el alma la que define la naturaleza corpórea $y$, de este modo, corrobora su definición de sí misma como primera verdad, también ha de estarlo que, con dichas premisas, se completa la radical escisión entre el pensamiento y la extensión, dualidad que —según Rodis-Lewis (1982) - constituye "la principal conclusión de la metafísica" cartesiana y que tiene como fundamento la existencia de Dios, del que todo depende: ser y certeza (p. 15). Pero la naturaleza de la materia extensa no ha de definirse con las características que le atribuyó el realismo escolástico y que, más tarde, serán retomadas por la física newtoniana, y tampoco los seres vivos podrán ser conceptuados como seres que se nutren, se mueven y sienten (Descartes, 1977a, pp. 4446). Quedaba, sin embargo, un punto por resolver: ¿cómo explicar la acción de las sensaciones sin postular una determinada unión de cuerpo-alma y una conservación de la misma? La segunda parte de los Principia y la sexta meditación están dedicadas a dicha explicación, pero no será en ellos, sino en el Traité de l'ame y en De passionibus animae donde el problema reciba un tratamiento menos condicionado por el dualismo.
Sin embargo, en ninguna de estas dos obras logró Descartes explicar racionalmente la conjunción de dos elementos: por un lado, la dualidad metafísica de mente-cuerpo y, por otro, el recurso a tres "hipótesis fisiológicas hidráulico-mecanicistas" para apuntar hacia un esclarecimiento del "misterio" de su unión: "persistencia de los galénicos 'espíritus animales', 'preponderancia anatómica de la glándula pineal' y 'consideración de los nervios como canales huecos"' (López-Muñoz y Álamo, 2000, p. 239).

A la luz de la neurobiología actual, puede afirmarse que Descartes abordó de forma errónea la localización de las funciones cerebrales, pero no podrá ponerse en duda que su Traité de l'homme puede ser considerado como el primer libro europeo de fisiología que marcó el modo de entender la psicofisiopatología en el siglo XVII y en gran parte del siglo XVIII. Abrió el camino para que Thomas Willis (1622-1675) estableciese que no era la glándula pineal, sino, más bien, el cerebelo, el asiento del alma sensitiva y la fuente de los espíritus animales. Y también hizo posible que, en el problema de la interacción mente-cuerpo, Jan Swammerdan realizase, a fines del siglo XVII, el primer experimento de electrofisiología y contribuyese a fundar la psicología empírica de corte inductivista. Siguiendo esta metodología científica, se abordó el estudio de la glándula pineal de los mamíferos desde una perspectiva ya no 
solo anatómica, sino también histológica y embriológica; posteriormente, en el siglo XIX, se trató de mostrar la similitud con la epífisis de los mamíferos $\mathrm{y}$ de otros animales vertebrados.

\section{A MODO DE CONCLUSIÓN}

La glándula pineal cartesiana, considerada como explicación pionera en lo que respecta a la interacción mente-cuerpo, implicaba, pese al planteamiento del terminante dualismo de las Meditaciones metafísicas, una fisura en el lugar donde habita la razón (es decir, en la conciencia). Prescindiendo de la ubicación y función actuales de la glándula pineal, el cometido que Descartes le asignó está vinculado claramente a la aporía planteada por la incomunicación de las sustancias. Si, por definición, ni la res cogitans ni la res extensa, autosuficientes en sí mismas y ontológicamente separadas, no se necesitan la una a la otra, ¿cómo explicar que aparezcan unidas entre sí en determinadas acciones humanas?

La psicología racional cartesiana, entendida como una rama de la metafísica especial que define al ser humano solo como razón pura, se justificaría totalmente si es que no existiese la mediación o puente, empíricamente constatable, entre la sustancia racional y la corpórea. Dicha mediación es la que vincula a Descartes con una antropología filosófica que no concibe al hombre como dualidad, sino como una unidad psicosomática. Deja, sin embargo, un problema abierto: la disputa por la primacía de las sustancias en cuanto a ser "sujetos de inhesión". En efecto, si se acepta la interacción entre mente-cuerpo, como es el caso de la antropología filosófica, entonces, pueden entrar a tallar, en la lucha por la voz de mando, el psicologismo, el materialismo y todas las interpretaciones poscartesianas que se han hecho sobre el "yo" (Kant, Fichte, Hegel, Nietzsche). Lleva razón Johannes Hirschberger (1970) cuando sentencia: "Cualesquiera que sean los caminos que recorre la antropología filosófica moderna, Descartes los ha abierto con su segunda meditación: $D e$ natura mentis humanae: Quod ipsa sit notior quam corpus" (p. 40).

Pero dicha apertura está menos vinculada al dualismo de sustancias que al intento cartesiano por vincularlas entre sí mediante la glándula pineal, auténtico quicio para fundamentar el tránsito de la psicología racional a la antropología filosófica. Es correcto afirmar que, desde la perspectiva dualista, el recurso cartesiano puede parecer una estrategia imposible de admitir, pero implica, de hecho, una cisura en el sustancialismo binario, ya que se introduce en la incomunicación de las dos sustancias una mediación que las interrelaciona. Como bien ha señalado José M. Bermudo (1983), en la filosofía de Descartes se sospecha que toda mediación en el conocimiento es un riesgo de ficción, $o$, en derivación de ello, que todo lo que se interponga entre el objeto real y el 
sujeto pensante ha de ser fuente de escepticismo. Sin embargo, dicha tesis, inferida claramente del dualismo, se ve contradicha cuando se apela a un nexo físico para que medie entre la mente y el cuerpo. Su conclusión, empero, implica que es el dualismo el que asume la mediación sin que se note su interferencia: "La indicación de que podría ser la glándula pineal el lugar privilegiado donde la relación se establece, no pasa de ser una metáfora" (pp. 23 y 27).

El problema de la comunicación entre lo sustancialmente distinto, legado por Descartes a la posteridad, evidencia que, en efecto, él no tuvo una propuesta concluyente acerca de su solución. Se lo impedía la inclusión de lo natural en un sujeto metafísico y en una metodología deductiva que, desde la razón, desacreditaba los logros de toda inducción producida por la experiencia. Pero la exclusión newtoniana, en Scholium generale (1713), de las hipótesis metafísicas del ámbito de las ciencias naturales, al exigir que estas solo admitiesen proposiciones fundamentadas en fenómenos y generalizadas inductivamente, iba a contribuir a recortar las aspiraciones totalizadoras del racionalismo. Robert Boyle, contemporáneo de Newton, sentenciará: "Una explicación total de las cosas no es el objeto de una ciencia experimental" (citado por Benítez, 2011, p. 202).

El accidentalismo ${ }^{4}$ - esto es, la explicación de las sustancias mediante lo que el racionalismo había recusado como fuente de verdad: los accidentes- reemplaza en la ciencia lo que Descartes, incluso como aristotélico, nunca hubiese admitido: que la epistéme (scientia) constituye la base de la sophía (sapientia). Pero "el espíritu, según parece, se ha domiciliado totalmente en finitudes; se ha hecho totalmente finito" (Büchner, 1978, p. 37). Dos siglos después de Descartes, en uno de los aforismos más conocidos de su Blüthenstaub (1798), afirmará Novalis: "Buscamos por todas partes lo incondicionado, pero lo único que encontramos siempre son cosas" (Wir suchen überall das Unbedingte, und finden immer nur Dinge) $)^{5}$.

4 En el empirismo no hay una metafísica de la sustancia y puede hablarse en él, antes bien, de un accidentalismo. La sustancia, afirma Hume en el Tratado de la naturaleza humana, no es sino una "idea" extraída "de una colección de cualidades particulares". En las Objetiones tertiae, cum responsionibus authoris (Adam y Tannery, 1957, VII, p. 175), T. Hobbes había escrito: "Puede ser que una cosa que piensa sea algo corpóreo". No otra cosa expresó Francis H. C. Crick (1906-2004), premio Nobel de Medicina (1962): "La idea del alma, como distinta del cuerpo y no sujeta a leyes científicas que conocemos, es un mito" (1994, p. 4).

5 Conviene señalar que la palabra Ding (en alemán, "cosa") está presente de manera negativa en das Unbedingte ("lo incondicionado", esto es, lo que no guarda relación con las cosas). En Descartes, las cosas no existirían sin Dios; por lo tanto, aunque Dios no sea una cosa finita, mantiene una relación ontológica de múltiples causalidades con las sustancias $($ res $=$ Dinge $)$ finitas. 
Cosas (res) fue el término empleado por Descartes para designar a las sustancias finitas, mas él sí encontró un ser (Dios) que no fuese "cosa incondicionada" (Unbedingt), sino la condición de posibilidad de todas las cosas existentes, tanto de las pensantes como de las extensas. Sin embargo, para explicar el hecho de la interacción de las sustancias finitas tuvo que recurrir a una "cosa" también finita: la glándula pineal. Si este recurso significa dar razón al materialismo filosófico en la explicación de la unidad psicosomática postulada por la antropología filosófica, no es aquí un tema pertinente. Pero sí lo es admitir que la búsqueda de un apoyo físico para esclarecer la relación mente-cuerpo no pertenece a la tesis que toda psicología racional lleva consigo: definir la naturaleza humana solo como alma.

También podrían incluirse como indicadores de la importancia que puede cobrar la res extensa, las denominadas antropologías biológicas. Leopoldo Prieto, sacerdote católico y profesor de Filosofía en el Ateneo Pontificio Regina Apostolorum (Roma), cree que ellas constituyen una "revolución copernicana de la antropología" y no niega la validez de que sea el cuerpo, y no el alma racional, el punto de partida para constituir la naturaleza humana (concepto, por cierto, al que las antropologías biológicas son poco adictas). Prieto afirma que en lo corpóreo se hace patente la racionalidad y rechaza el reduccionismo, que implica, según él, la "reinterpretación del hombre en clave animalista", pero atribuye al cuerpo humano ser el correlato físico del alma en las criaturas racionales (2008, pp. XV-XX). No identifica el pensamiento con la actividad nerviosa y cerebral, y, por tanto, al igual que Descartes, reafirma su inmaterialidad. Pero la adopción del punto de partida (el cuerpo humano, y no el espíritu) permite atisbar en Prieto una suerte de materialismo antropológico que, desde luego, sería impensable en Descartes, a no ser que en sus reflexiones sobre la glándula pineal hubiese desistido del dualismo.

La filiación medieval de Descartes (1977a) queda negada cuando atribuye la posibilidad de la autoría de las cogitationes (ideas, esencias) al alma (p. 42). Hasta entonces, en aceptación del realismo platónico, las ideas eran trascendentes al espíritu, pero "con Descartes [tal como escribe Yvon Belaval (1982)], la idea verdadera, innata $\mathrm{y}$, en consecuencia, garantizada por la veracidad divina se hace inmanente al espíritu humano". Y, en constatación histórica que deviene en lúcido interrogante, añade:

Será suficiente que Locke rebaje esta inmanencia de la ontología a la psicología para que la metafísica — quizá solo la tradicional- se tambalee. Después de haber meditado sobre Dios y el mundo, ¿se constituirá un día el hombre en objeto exclusivo de la filosofía? (p. 6). 
La metafísica especial (Dios, mundo, ser humano) no puede entenderse, en tanto exclusivamente cartesiana, sin Dios. A Él habría que cargarle la responsabilidad de ser, en último término, el agente causal de la "misteriosa" interacción mente-cuerpo. Pero, incluso abandonando cualquier hipótesis teológica, no parece posible que el problema del hombre se constituya en el objeto único de la reflexión filosófica si, como fue el caso de Descartes, la psicología racional no cede su lugar a la antropología filosófica.

Al igual que Arquímedes pedía un punto de apoyo firme e inmóvil (punctum... firmum et immobile) para, con una hipotética palanca, trasladar a la Tierra de lugar, así también Descartes (1977a) abrigaba la esperanza de encontrar una verdad primera sobre la que levantaría todo el edificio de las ciencias y de la filosofía (p. 42). Creyó, desde luego, haberla conseguido. Pero, al rebajar la materia y la corporalidad somática a un nivel ontológico inferior, el punto arquimédico cartesiano de apoyo se hizo más leve y vacilante, constituyendo el recurso a la glándula pineal, como intento de solución de la interrelación alma-cuerpo, el mejor testimonio de su inseguridad. Sin embargo, la premonición de Descartes (1987), en su carta al traductor de los Principia, no puede, en este sentido, ser más elocuente: "La mayoría de las verdades que restan por encontrar dependen de algunos experimentos particulares y no se encontrarán jamás por azar, sino que deben ser buscadas con cuidado y muchos gastos por hombres muy inteligentes" (p. 19).

Descartes legó a la posteridad un problema irresuelto y, por lo que se ve, tan cargado de polémica e incógnitas como lo es la pregunta que tanto Platón (Teetetes) como Kant (Logik) consideraron crucial en la filosofía: “¿Qué es el hombre?". Todo habla a favor de que a dicha pregunta le corresponden tan solo respuestas fragmentadas e inconclusas. Descartes es un testimonio "claro y distinto" de que, efectivamente, ello es así.

\section{REFERENCIAS}

Adam, Ch. \& Tannery, P. (1957-1958). Oeuvres de Descartes. París: J. Vrin. Anzenbacher, A. (1980). Einführung in die Philosophie. Friburgo: Herder.

Aristóteles (1988). Tratados de lógica (Órganon) (dos tomos). Madrid: Gredos.

Aristóteles. (1990). Metafísica. Madrid: Gredos.

Belaval, Y. (1982). Introducción. La época clásica. En Belaval Y. (Director), Historia de la filosofía (volumen 6, pp. 1-6). Madrid: Siglo XXI.

Benítez, H. (2011). Ensayos sobre ciencia y religión. De Giordano Bruno a Charles Darwin. Santiago de Chile: RIL. 
Bermudo, J. M. (1983). La filosofía moderna y su proyección contemporánea. Barcelona: Barcanova.

Boring, E. G. (1999). Historia de la psicología experimental. México D. F.: Trillas.

Büchner, H. (1978). Espíritu. En Krings, H., Baumgartner, H. M., \& Wild, C., Conceptos fundamentales de filosofía (volumen 1, pp. 27-39). Barcelona: Herder.

Caparrós, A. (1980). El proyecto psicológico de Wundt en Heidelberg. Anuario de Psicología, 23, 5-15.

Crick, F. H. C. (1994). La búsqueda científica del alma. Madrid: Debate.

Descartes, R. (1977a). Meditationes de prima philosophia. Hamburgo: F. Meiner.

Descartes, R. (1977b). Meditaciones metafísicas con objeciones y respuestas. Madrid: Alfaguara.

Descartes, R. (1980). Tratado del hombre. Madrid: Nacional.

Descartes, R. (1987a). Discurso del método. Madrid: Alhambra.

Descartes, R. (1987b). Los principios de la filosofía. México D. F.: UNAM.
Descartes, R. (1989). El mundo. Tratado de la luz. Madrid: Anthropos.

Descartes, R. (1990). Tratado sobre el hombre. Madrid: Alianza.

Hirschberger, J. (1970). Historia de la filosofía. Barcelona: Herder.

López-Muñoz, F., y Álamo, C. (2000). El tratado del hombre: interpretación cartesiana de la neurofisiología del dolor. Asclepio, 52, 239-268.

Migne, J. P. (1996) [2013]. Patrologia Latina Database. Recuperado el 3 de junio de 2013 de http://pld.chadwyck.co.uk/ (obra original publicada en 1844-1855).

Pérez de Laborda, M. (1996). Sujeto, propio y esencia: el fundamento de la distinción aristotélica de los modos de predicar. Acta Philosophica, 5, 269-292.

Prieto, L. (2008). El hombre y el animal: nuevas fronteras de la antropología. Madrid: BAC.

Rodis-Lewis, G. (1982). Descartes. Cartesianos y anticartesianos franceses. En Y. Belaval (Director), Historia de la Filosofía (volumen 6, pp. 7-56. Madrid: Siglo XXI. 